BIOTROPIA No. 12, 1999 : 25 - 30

\title{
THE EFFECTS OF a-CHLOROHYDRIN ON THE GESTATION OF THE WISTAR RAT (Rattus norvegicus)
}

\author{
RAHMANIAH \\ Department of Biology, University ofHaluoleo, Kendari, Indonesia \\ And
}

LIEN A.. SUTASURYA

Department of Biology, Bandung Institute of Technology, Bandung, Indonesia

\begin{abstract}
The investigation of the effects of a-chlorohydrin on the gestation of the wistar rat has been carried out to determine whether a-chlorohydrin could interfere with the gestation of the rat and gestation period for optimal sensitivity. Alpha-chlorohydrin was administered by gavage to three different groups of pregnant rats, namely on the first (pre-implantation period), sixth (early postimplantation period) or fourteenth (late post-implantation period) gestation day, at a single dose of 62.5; 75 and $90 \mathrm{mg} / \mathrm{kg}$ body weight. Rats were sacrificed on the IS* gestation day. Number of implantations, gestation loss and post-implantation mortality were recorded. The results revealed that 75 and $90 \mathrm{mg} / \mathrm{kg}$ body weight of a-chlorohydrin significantly interfered with all the gestation periods used. For the preimplantation group, a-chlorohydrin decreased significantly the implantation number, but increased the gestation loss as well as the post-implantation mortality compared to the control groups. For the early post-implantation and late post-implantation groups, a-chlorohydrin caused a significant increase in post-implantation mortality compared to the control groups. From these results it is concluded that achlorohydrin at 75 and $90 \mathrm{mg} / \mathrm{kg}$ body weight influences the gestation of the wistar rat administered during the pre-implantation period as the most sensitive gestation period.
\end{abstract}

Key words : a-chlorohydrin//tattu? norvegi'ctu/rat/pre-implantation/early post-implantation/late postimplantation/implantation/gestation loss/post-implantation mortality.

\section{INTRODUCTION}

Rats comprise a major pest that often causes substantial financial loss to agriculture. There are several ways to control rat populations. For example, exposure of rats to rodenticides to kill the rats. The disadvantage of this approach is that rats will stay away from sites populated with dead rat remains. As a result, rats will move to other areas. Another disadvantage is that rodenticides are likely to kill other animals.

To control rat populations effectively and without detriment to other animals, it is essential to explore alternative approaches. One of the best alternatives is to use a chemical agent that would reduce fertility in rats without the need to kill them. Investigations conducted during the past 35 years were carried out with steroid and non-steroid agents. Among the non-steroid compounds, only a-chlorohydrin produced the ideal contraceptive effects in male rats (Jones 1983). The results 
indicated that low dosages of a-chlorohydrin reduced fertility in males but this effect was reversible. At relatively high dosages, a-chlorohydrin effectively caused sterility in male rats. Successful infertility has also been reported for a-chlorohydrin in boar (Stevenson and Jones 1982; 1985), rats (Tsunoda and Chang 1976; Brown-Woodman et al. 1979; Paz and Homonnai 1982), and Macaca mullata (Kirton el al. 1970).

To achieve optimization of control of rat populations, successful contraception of females is essential. Paz and Homonnai (1982) reported that oocytes in female rats inseminated with sperm carrying low levels of a-chlorohydrin did not develop. Although Gao and Short (1993) could not demonstrate that a-chlorohydrin produced an antifertility effect in female rats, we decided to investigate the effect of achlorohydrin on pregnancy. Our results show that a-chlorohydrin significantly interfered with rat gestation.

\section{METHODS AND MATERIALS}

This investigation was carried out on female rats, Rattus norvegicus Wistar, 90100 days old and a body weight of 180-200 gram. The antifertility drug, achlorohydrin, used in this study was supplied by Sigma Chemical at a concentration ofl.32g/ml.

The general procedure used was as follows. Female rats were mated in the afternoon, and the following day, a vaginal smear was obtained to determine the presence of sperm. When sperm was detected, the rats were designated to be in their first day of gestation. Pregnant rats were divided into four groups of six rats per group. A single dose of a-chlorohydrin was administered by gavage on the first day of gestation (pre-implantation period), repeated on the sixth day of gestation (early post-implantation period) and again on the fourteenth day of gestation (late postimplantation period). One group of rats received treatments of $62.5 \mathrm{~g} / \mathrm{kg}$ body weight of a-chlorohydrin, the second group received $75 \mathrm{mg} / \mathrm{kg}$ body weight and third group received $90 \mathrm{mg} / \mathrm{kg}$ body weight of the drug. The control group received distilled water.

The rats were sacrified on the eighteenth day of gestation. The ovaries were removed and placed in $9 \% \mathrm{NaCl}$. The uterus was cut opposite the implantation sites. The number of implantations, live fetuses, dead fetuses and resorption of embryos were recorded. The ovaries were microscopically examined and the corpus lutea were recorded. From these data, the following reproduction parameters were calculated for every rat:

$$
\text { Percentage of implantation }=\frac{\text { number of implantations }}{\text { number of corpus lutea }} \times 100 \%
$$


The effects of a-Chlorohydrin on the Gestation of the Wistar Rat - Rahmaniah and L.A. Sutasurya

number of corpus lutea - number of implantations

Percentage of gestation loss = $\mathrm{x} 100 \%$

Number of implantations

number of live fetuses

Percentage of Post-implantation Mortality =

number of implantations

The data were statistically analyzed for significance in difference by the LSD test.

\section{RESULTS AND DISCUSSION}

Pre-Implantation Period

The pre-implantation period showed that at dosages of 75 and $90 \mathrm{mg} / \mathrm{kg}$ body weight gestation loss and post-implantation mortality increased significantly compared to the controls. Whereas implantation showed a significant decrease (see Table 1 and Figure 1), the dosage of $62.5 \mathrm{mg} / \mathrm{kg}$ body weight ct-chlorohydrin produced no difference in implantation, gestation loss, and post-implantation mortality from the controls.

Table 1. Percentage of implantation, gestation loss (GL), and post-implantation mortality (PIM) for achlorohydrin treatments compared to control for all of the gestation periods

\begin{tabular}{|c|c|c|c|c|c|}
\hline $\begin{array}{c}\text { Gestation } \\
\text { Period }\end{array}$ & $\begin{array}{c}\text { Dose } \\
\text { (mg/kg b.w.) }\end{array}$ & $\begin{array}{c}\text { Number of } \\
\text { rats } \\
\text { examined }\end{array}$ & $\begin{array}{c}\text { \% Implantation } \\
(\mathrm{X} \pm \mathrm{SD})\end{array}$ & $\begin{array}{c}\text { \%GL } \\
(\mathrm{X} \pm \mathrm{SD})\end{array}$ & $\begin{array}{c}\text { \% PIM } \\
(\mathrm{X} \pm \mathrm{SD})\end{array}$ \\
\hline Pre- & 0 & 6 & $93.8 \pm 0.3^{\prime}$ & $6.2 \pm 1.2^{\prime \prime}$ & $1.9 \pm 1.0^{\prime \prime}$ \\
implantation & 62.5 & 6 & $93.3 \pm 0.3^{1}$ & $6.7 \pm 1.3$ & $6.1 \pm 1.3^{*}$ \\
$\left(1^{\prime \prime}\right.$ GD) & 75 & 6 & $79.6 \pm 0.4^{\prime \prime}$ & $20.4 \pm 0.7^{\prime \prime}$ & $16.7 \pm 1.5^{\mathrm{bc}}$ \\
& 90 & 6 & $77.7 \pm 0.6^{\prime \prime}$ & $22.3 \pm 1.0^{*}$ & $25.3 \pm 1.1^{\mathrm{c}}$ \\
\hline Early post- & 0 & 6 & $94.7 \pm 0.3^{\prime \prime}$ & $5.3 \pm 1.5^{\mathrm{a}}$ & $4.7 \pm 1.4^{*}$ \\
implantation & 62.5 & 6 & $94.8 \pm 0.3^{\prime}$ & $5.1 \pm 1.4$ & $5.4 \pm 1.4^{\prime}$ \\
$\left(\mathrm{e}^{\wedge}\right.$ GD) & 75 & 6 & $92.6 \pm 0.8^{\prime}$ & $8.0 \pm 2.2^{\prime}$ & $25.0 \pm 1.0^{\prime \prime}$ \\
& 90 & 6 & $89.8 \pm 0.9^{*}$ & $10.2 \pm 2.3^{\prime}$ & $39.8 \pm 1.6^{\mathrm{C}}$ \\
\hline Late post- & 0 & 6 & $93.8 \pm 0.3^{\prime \prime}$ & $6.1 \pm 1.4^{\prime}$ & $4.3 \pm 1.4^{\prime \prime}$ \\
implantation & 62.5 & 6 & $90.2 \pm 0.7^{1}$ & $9.8 \pm 2.1^{\prime}$ & $5.4 \pm 1.4^{\prime}$ \\
$\left(14^{1 \prime \prime}\right.$ GD) & 75 & 6 & $87.6 \pm 08^{*}$ & $12.4 \pm 2.4^{*}$ & $20.7 \pm \mathrm{U}^{\mathrm{C}}$ \\
& 90 & 6 & $89.6 \pm 0.3^{\prime}$ & $10.4 \pm 1.3^{\prime}$ & $24.3 \pm 1.0^{\mathrm{cd}}$ \\
\hline
\end{tabular}

b.w = body weight GD = gestation day Number followed by the same letter indicate that they are not significantly different (LSD test at $\mathrm{p}<0.05)$. 


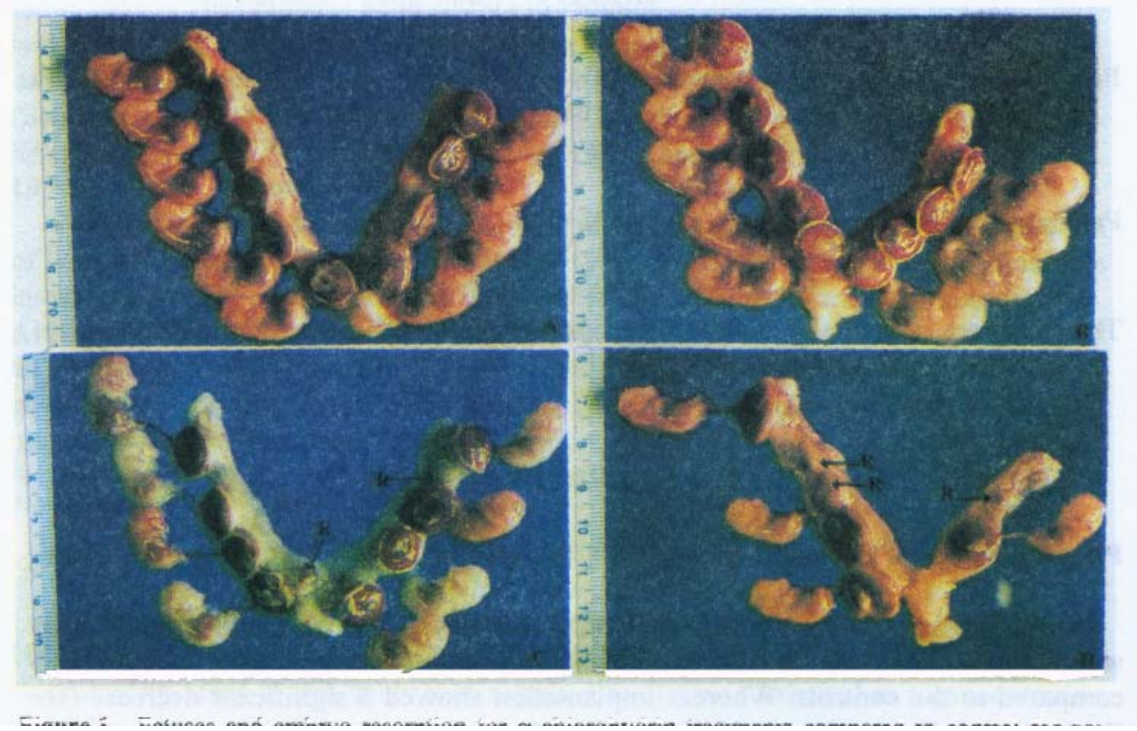

Figure 1. Fetuses and embryo resorption for a-chlorohydrin treatments compared to control for preimplantation period ( $l^{\mathrm{a}}$ gestation days).

\section{Early Post-Implantation Period}

At dosages of 75 and $90 \mathrm{mg} / \mathrm{kg}$ body weight, post-implantation mortality increased significantly, but implantation and gestation loss were not statistically different, compared to the controls (see Table 1). At a dosage of $62.5 \mathrm{mg} / \mathrm{kg}$ body weight, a-chlorohydrin produced no difference in implantation, gestation loss, and post-implantation mortality from the controls.

\section{Late Post-Implantation Period}

At dosages of 75 and $90 \mathrm{mg} / \mathrm{kg}$ body weight, post-implantation mortality increased significantly compared to the controls. However, at these dosages implantation and gestation loss were not affected by a-chlorohydrin. At $62.5 \mathrm{mg} / \mathrm{kg}$ body weight, a-chlorohydrin had no effect on implantation, gestation loss, and postimplantation mortality.

In all three implantation periods, a-chlorohydrin produced no difference in number of corpus lutea, live fetuses, and dead fetuses compared to the controls. 
The results obtained in this investigation clearly showed that a-chlorohydrin at 75 and $90 \mathrm{mg} / \mathrm{kg}$ body weight interferes with pregnancy when administered at all three gestation periods used, and administration during the pre-implantation period generally as the most effective stage. The agent's antifertility effect was most pronounced at $90 \mathrm{mg} / \mathrm{kg}$ body weight. At $62.5 \mathrm{mg} / \mathrm{kg}$ body weight the result was not significantly different from that of the control groups. Alpha-chlorohydrin significantly decreased implantation and increased both gestation loss and postimplantation mortality. Alpha-chlorohydrin decreased fertility by more than $50 \%$ and, therefore, qualifies as an antifertility drug.

The mechanism of action of a-chlorohydrin in female rats is not known. In male rats, it is converted to 3-chlorolactaldehyde, which inhibits glycolysis and reduces ATP synthesis in the sperm mitochondrion because less pyruvic acid is available for import into the organelle (Stevenson and Jones 1985). Administration of a-chlorohydrin during the pre-implantation period decreased implantation and increased gestation loss. It is conceivable that the effects were caused by the drug as a result of impairment of transport of the zygote via the oviduct to the uterus, facilitated by muscle contraction and ciliar movement. This requires expenditure of a considerable amount of energy by way of ATP supply (Johnson and Everitt 1988). This might reduce the transport rate of fertilized eggs and cause arrival of the zygote at implantation sites beyond the requisite period of $5^{\text {th }}$ to $6^{\text {th }}$ day of gestation.

Since administration of a-chlorohydrin during the pre-implantation period resulted in a decrease in implantation and increased post-implantation mortality in the course of eighteen days, this long-term effect may be attributed to storage of achlorohydrin in body fat to prolong its effect (Paz and Homonnai 1982). To account for the higher values of post-implantation mortality when the drug was presented in the early post-implantation period as compared to the results obtained when treatment occurred in the late post-implantation period, it is conceivable that the placental barrier, once completely formed during post-implantation treatment, may have reduced transfer of the drug and lower embryo resorption (Juchau 1981). The present study supports the role of a-chlorohydrin as an effective antifertility drug in female rats.

\section{REFERENCES}

BROWN-WOODMAN, P.D.C., I.G. WHITE and D.D. RIDLEY, 1979. The antifertility activity and toxicity of

a- chlorohydrin derivatives in male rats. Contraception. 19: 517-527.

GAO, Y. and R.V. SHORT. 1993. Use of estrogen, androgen or gestagen, a potential chemosterilant for control of rat and mouse population. J. Reprod. Pert. 97: 30-49.

JOHNSON, M. and B. EVERITT. 1988. Essential reproduction. Blackwell Scientific Publications. Oxford.

JONES, A.R. 1983. Antifertility actions of a-chlorohydrin in the male. Aust. J. Biol. Sci. 36: 333-350.

JUCHAU, M.R. 1981. The biochemical basis of chemical teratogenesis. Elsevier/North-Holland.

Amsterdam. P.3 \& 85. 
BIOTROPIA No. 12,1999

KIRTON,K.T., R.J. ERICSON,J.A. RAY, and A.D. FORBES. 1970. Male antifertility compounds, efficacy of U-5897 in primates (Macaca mullata). J. Reprod. Pert. 21. 275-278.

PAZ, G.F. and T.Z. HOMONNAI. 1982. A direct effect of a-chlorohydrin on rat epididymal spermatozoa. Int. J. Androl. 5:308-316. STEVENSON,D. and A.R. JONES. 1982. Inhibition of fnictolisis in boar

spermatozoa by male antifertility agents (S>0.-chlorohydrm. Aust. J. Biol. Sci. 35: 595-605.

STEVENSON, D. and A.R. JONES. 1985. Production of 3-chlorolactaldehyde from a-chlorohydrin by boar spermatozoa and inhibition of glyceraldehyde-3-phosphate dehydrogenase in vitro. J. Reprod. Pert. 74: 157-165.

TSUNODA, Y. and M.N. CHANG, 1976. Fertilizing ability in vivo spermatozoa of rat and mice treated with achlorohydrin. J. Reprod. Fert. 46: 401-406. 